\title{
EFFECT OF THE CAPPING AGENT ON THE OPTICAL ABSORPTION EDGE OF COPPER OXIDE NANOPARTICLES FILM
}

\author{
E. Albrasi*1, S. Almabrok², and P. John. Thomas ${ }^{3}$ \\ ${ }^{1}$ Faculty of Education University of Benghazi \\ ${ }^{2}$ Faculty of Science, University of Benghazi. \\ ${ }^{3}$ School of Natural Sciences, University of Bangor, U.K.
}

\begin{abstract}
In this work, the capped and uncapped copper oxide $(\mathrm{CuO})$ nanoparticles film with an average size ranging from 8.7- $6.2 \mathrm{~nm}$ have been prepared by a chemical wet procedure using copper (II) sulfate with sodium hydroxide at $50{ }^{\circ} \mathrm{C}$. The EDTA was used as a capping agent and the obtained samples were investigated by UV visible spectrum. The uncapped and EDTA capped $\mathrm{CuO}$ nanoparticles reveals two bands observed at $310 \mathrm{~nm}$ and $232 \mathrm{~nm}$ for uncapped and EDTA capped $\mathrm{CuO}$ nanoparticles respectively. The optical absorption spectra exhibits the energy band gap for uncapped and EDTA capped $(\mathrm{CuO})$ in the range of $(3.8-4.5) \mathrm{eV}$ respectively.
\end{abstract}

Keywords: Optical band gap, $\mathrm{CuO}$ nanoparticles, capping agent.

\section{Introduction}

Nanoparticles of metal oxide have attracted the amount of attention over recent years, because of the distinction of their physical and chemical properties. Among all other metal oxides, Copper oxide $(\mathrm{CuO})$ is a material that possesses scientific and industrial applications (Jolivet, 2000) in the areas of magnetic storage media and photonic devices (Mishina et al.,2001; Cao et al.,2008) due to, their unique properties like superconductors and photovoltaic properties. (Frietsch et al.,2000; Sukhorukov et al.,1998; Carnes and Klabunde,2003).

$\mathrm{CuO}$ is a p-type semiconductor oxide, with a narrow indirect band gap of $\sim 1.21 \mathrm{eV}$, and high absorption properties that make it a promising for solar cell fabrication (Xia et al.,2014; Masudy et al.,2013; Kumar et al.,2013). Efforts of researchers have been made for synthesizing $\mathrm{CuO}$ nanoparticles by using different methods such as thermal decomposition (Darezereshki and Bakhtiari,2011), sol-gel (Hong et al.,2002), chemical precipitation (Tran and Nguyen,2014). as well as electrochemical methods (Son et al., 2009; Poizot et al., 2003 and Yuan et al., 2007) in which various nano morphologies can be acquired.

Nanoparticles in the way of films can be utilized for solar energy. Therefore, it is considered desirable to develop the method to synthesize high-quality thin film of $\mathrm{CuO}$ nanoparticles for device fabrication. In this paper, reacting $\mathrm{CuSO}_{4} .5 \mathrm{H}_{2} \mathrm{O}$ as the source of $\mathrm{Cu}$ and an aqueous 
$\mathrm{NaOH}$ solution in the presence of EDTA as a capping agent, we could obtain film of $\mathrm{CuO}$ nanoparticles at the interface.

\section{Experimental section}

\section{Chemical reagents}

Copper (II) sulfate pentahydrate and sodium hydroxide pellets obtained from T-Baker Lab Chemicals, India, EDTA and toluene from BDH chemicals Ltd Poole, England

\section{Synthesis of $\mathrm{CuO}$ nanoparticles}

$50 \mathrm{ml}(0.437 \mathrm{~g})$ copper (II) sulfate pentahydrate as the $\mathrm{Cu}$ source in $20 \mathrm{ml}$ of toluene was taken in a beaker and $20 \mathrm{ml}$ of an aqueous solution containing $1.2 \mathrm{~g}$ of $\mathrm{NaOH}$ was slowly injected into the beaker was placed inside oven left undisturbed at $50{ }^{\circ} \mathrm{C}$ for $8 \mathrm{~h}$.

$$
\begin{gathered}
\mathrm{CuSO}_{4} .5 \mathrm{H}_{2} \mathrm{O}+2 \mathrm{NaOH} \rightarrow \mathrm{Na}_{2} \mathrm{SO}_{4}+\mathrm{Cu}(\mathrm{OH})_{2}+5 \mathrm{H}_{2} \mathrm{O} \\
\mathrm{Cu}(\mathrm{OH})_{2} \rightarrow \mathrm{CuO}+\mathrm{H}_{2} \mathrm{O}
\end{gathered}
$$

The achievement of the reaction was indicated by the appearance of black colour at the interface as shown in figure1. Reactions were similarly carried out by using $0.002 \mathrm{mM}$ of 10 ml EDTA as a capping agent, which added to $\mathrm{NaOH}$ and injected to the bottom of the beaker.

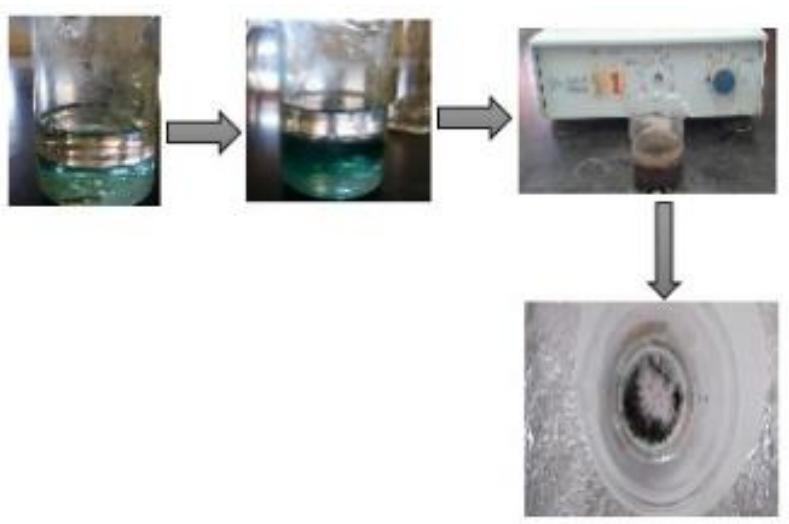

Figure (1): Photographs Show the Preparation of Cuo Film of Nanoparticles

The interfacial film of uncapped and EDTA capped $\mathrm{CuO}$ nanoparticles were dissolved in ethanol and quartz cell were used for the measurements. The as-prepared $\mathrm{CuO}$ nanoparticle thin films were analyzed by CE7400-7000 3ERIES Double Beam UV-vis spectrophotometer manufacture Buck scientific, Inc. The scan distance range was between 200-800 nm. The absorption spectra were recorded at room temperature. In this study, a simple UV-vis was 
utilized to calculate the bandgap energy using the Tauc relation (Tauc and Editor,1974; Litton and Reynolds,1964; Manjunath, 2016).

$$
(\alpha h v)=A(h v-E g)^{n}
$$

Here, Eg is bandgap, A is constant related to the material, $\alpha$ is absorption coefficient, $\mathbf{h v}$ is photon energy, $\mathrm{n}$ is 2 for direct transition or $1 / 2$ for an indirect transition.

\section{Result and dissection}

The UV-vis spectrum of the uncapped and EDTA capped copper oxide nanoparticles exhibits absorption peaks centered at $310 \mathrm{~nm}$ and $232 \mathrm{~nm}$ (figure.2). It reveals the peak position and the maximum absorption ( $\lambda$ max) blue-shifted from $310 \mathrm{~nm}$ in uncapped $\mathrm{CuO}$ nanoparticles to $232 \mathrm{~nm}$ in EDTA capped $\mathrm{CuO}$ because of direct transition of electrons from the valence band to the conduction band as well as quantum confinement effect which occurs when particles size becomes as good as with or less than exciton Bohr radius. (Yin et al., 2005; Rahdar.,2015; Sawsan et al.,2014).

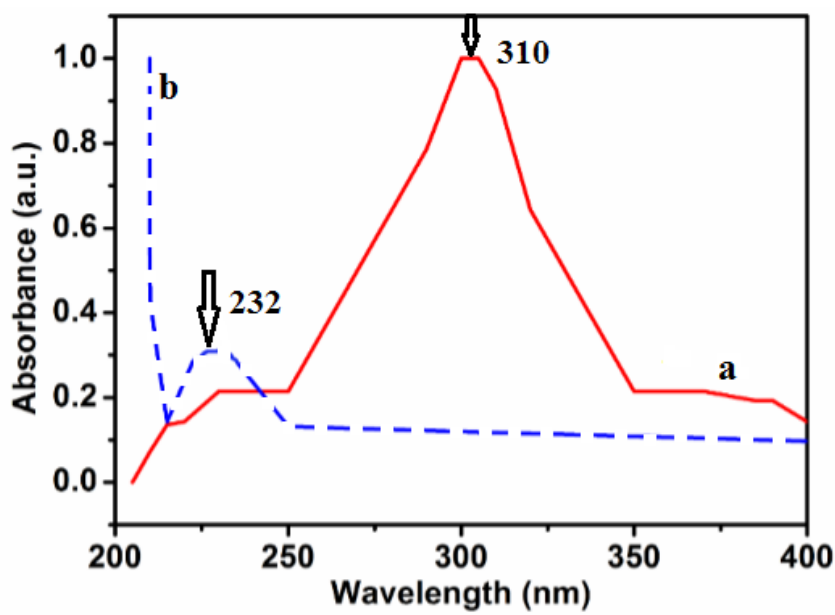

Figure (2): Absorption Spectra of Film Copper Oxide (a) Uncapped CuO Nanoparticles, (b) EDTA Capped $\mathrm{CuO}$ of Nanoparticles.

The absorbance against wavelength plots was changed to tauc plot and band gap energy was calculated by using tauc's equation by plotting $(\alpha h v)^{2}$ against hv (figure 3 ). The extrapolation straight line is obtained for all prepared samples gives the value of the absorption edge. The calculated band gap values of $\mathrm{CuO}$ nanoparticles are $3.8 \mathrm{ev}$ in uncapped and $4.5 \mathrm{ev}$ in EDTA capped $\mathrm{CuO}$ nanoparticles. Both the values are higher than the recorded value bulk $(1.21 \mathrm{ev})$ This redshift in energy band gap due to size reduction and the quantum confinement effect (Siddique et al., 2014; Loubaba et al., 2018; Yuan et al., 2019). 

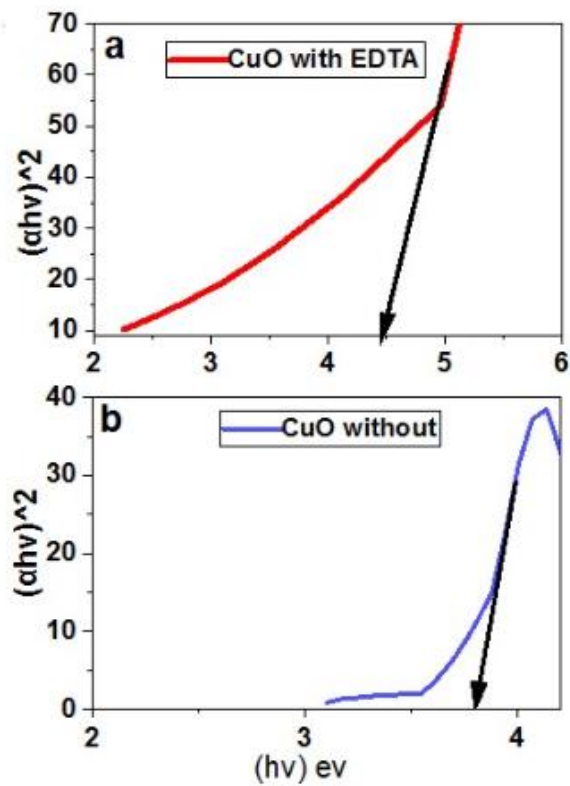

Figure (3): The Tauc Plots Used to Determine the Optical Band Gaps of CuO Nanoparticles (a) EDTA Capped CuO Nanoparticles, (b) Uncapped CuO Nanoparticles.

The particles size that estimated from UV absorption spectra using the formula below Was in the range of $8.7 \mathrm{~nm}$ in uncapped $\mathrm{CuO}$ and $6.2 \mathrm{~nm}$ in EDTA capped $\mathrm{CuO}$ (Phoka et al., 2009.; Purushottam et al., 2016).

$$
\mathbf{E g}=\mathbf{E}_{\text {bulk }}+\frac{h \pi}{2 R^{2\left(\frac{1}{m e}+\frac{1}{m h}\right)}}-1.8 e^{2} / \varepsilon R
$$

Eg is band gap energy of the nanoparticle, which will be determined from the UV-Visible absorbance spectrum, $\mathrm{E}$ bulk for $\mathrm{CuO}$ nanoparticles which is $1.21 \mathrm{ev}$,h is Planck's Constant, $\mathrm{R}$ nanoparticles size, $\mathrm{m}_{\mathrm{h}}$ and $\mathrm{m}_{\mathrm{e}}$ are effective mass for electrons and hole, $\mathrm{e}=1.602 \times 10^{-19} \mathrm{C}, \varepsilon$ is dielectric constant.

\section{Conclusion}

The $\mathrm{CuO}$ nanoparticles were successfully created by a facile method at comparatively low temperature. The optical band gap of $\mathrm{CuO}$ nanoparticles was found to be larger than the bulk band gap value $(1.21 \mathrm{eV})$ as expected due to the nano size of the particles. This work can lead to the synthesis of various mixed metal oxides for applications for solar energy or supercapacitors.

\section{Acknowledgement}

The author would like to think faculty of science university of Benghazi/Libya for encouragement. 


\section{References}

- Cao, J.L., Shao G.S., Wang Y., Liu Y., Yuan Z.Y, (2008).' CuO catalysts supported on attapulgite clay for low temperature CO oxidation' Journal of Catalysis. Communications. 9(15), pp,2555-2559.

- Carnes, C.L. and Klabunde, K.J. (2003) 'The catalytic methanol synthesis over nanoparticle metal oxide catalysts' Journal of Molecular Catalysis: A Chem. 194(1-2), pp. 227-236.

- Darezereshki, E. and Bakhtiari, F. (2011). 'A Novel Technique to Synthesis of Tenorte (CuO) Nanoparticles from Low Concentration CuSO4 Solution'. Journal of Mining and Metallurgy, Section B: Metallurgy, 47(1), pp.73- 78.

- Frietsch, M. F. Zudock, J. Goschnick, and Bruns, M. (2000) 'CuO catalytic membrane as selectivity trimmer for metal oxide gas sensors' Journal of Sensors and Actuators, B: Chem, 65(1), pp. 379-381.

- Hong, Z. Cao, Y. Deng, J. (2002) 'A Convenient Alcohothermal Approach for Low Temperature Synthesis of CuO Nanoparticles' Journal of Materials Letters, 52(1) pp. 34-38.

- Jolivet, J. P. (2000) 'Metal Oxide Chemistry and Synthesis'; Wiley: Chichester Kumar V., Masudy-Panah S., Tan C. C., Wong T. K. S., Chi D. Z., Dalapati G. K. Copper oxide based low cost thin film solar cells. Proceedings of the IEEE 5th International Nanoelectronics Conference (INEC '13); January 2013; pp. 443-445.

- Litton, C.W. and Reynolds, D.C. (1964) 'Double-carrier injection and negative resistance in CdS' Journal of physical. Review.133 (2A), pp. 536-41.

- Loubaba, A. Boujemaa, J. Hamid, G. (2018) ' effect of annealing temperature on structural, optical and photo catalytic properties of $\mathrm{CuO}$ nanoparticles' journal of chemistry7(5), pp.308316.

- Manjunath, A.Irfan, M. Kabbinadavamsha, P.A. Karuba,M.V.Narasimhappa,Y. (2016) 'Synthesis and characterization of $\mathrm{CuO}$ nanoparticles and $\mathrm{CuO}$ doped PVA nanocomposites' Journal of Advances in materials physics and chemistry.7.pp.263-273.

- Mishina,D.E. K. Nagai, S. Nakabayashi. (2001) 'Self-assembled $\mathrm{Cu} / \mathrm{Cu}_{2} \mathrm{O}$ multilayers deposition, structural and optical properties' journal of Nano. Lett ,1(8), pp.1401-404.

- Masudy-Panah. Kumar, S. V. Tan, C. C, Radhakrishnan, K.Chi, D. Z. Dalapati, G. K. (2013) 'Proceedings of the IEEE 5th International Nanoelectronics Conference (INEC '13)' 378. 
- Poizot, P. Hung, C.Nikiforov, M. Bohannan, E. W. and Switzer, J. A. (2003). 'An Electrochemical Method for $\mathrm{CuO}$ Thin Film Deposition from Aqueou Solution'. Journal of Electrochemical and Solid-State Letters 6(2), pp. 21-25.

- Purushottam, K.S. Pankaj, K.Manowar.H. Alok,K .and Ganesh.C.N.(2016). 'Synthesis and characterization of $\mathrm{CuO}$ nanoparticles using strong base electrolyte through electrochemical discharge process' Journal of Bull mater science.39. (2). pp.469-478.

- Phoka, S. Laokul, P.Swatsitang, E. Promarak ,V. Seraphin, S and Maensiri, S. (2009)' Synthesis, structural and optical properties of $\mathrm{CeO} 2$ nanoparticles synthesized by a simple polyvinyl pyrrolidone (PVP) solution route ' journal of Mater. Chem. Phys.115 (1). pp. 423428.

- Rahdar, A. Aliahmad, M. and Azizi, Y. (2015) 'NiO nanoparticles: synthesis and characterization' Journal of Nanostructures. 5, (2), pp. 145-151.

- Sawsan, D. Yousef, H. Ayesh. A and Nacir. T. (2014) 'Synthesis and optical properties of colloidal CuO nanoparticles' Journal of luminescence, 151. pp.149-154.

- Siddique, H. Qureshi, M. S. and Haque, F. Z. (2014) 'Structural and Optical Properties of CuO Nanocubes Prepared through Simple Hydrothermal Route'. International Journal of Scientific and Engineering Research, 5 (3). pp.173-177.

- Son, D. I.You, C. H. Kim, T. W. (2009). 'Structural, Optical, and Electronic Properties of Colloidal CuO Nanoparticles Formed by Using a Colloid-Thermal Synthesis Process'. Applied Surface Science, 255(21). pp. 8794-8797.

- Sukhorukov, Y.P. Loshkareva, N.N. Samokhvalov, A.A. Naumov, S.V. Moskvin, A.S. and Ovchinnikov, A.S. (1998) 'Magnetic phase transitions in optical spectrum of magnetic semiconductor $\mathrm{CuO}^{\prime}$. Journal of magnetismand magnetic materials,183(3), pp. 356-358.

- Tauc, J. (1974) 'Amorphous and Liquid Semiconductors' Plenum Press, London \& New York., pp.441.

- Tran, T. H. and Nguyen, V. T. (2014) 'Copper Oxide Nanomaterials Prepared by Solution Methods, Some Properties and Potential Applications' A Brief Review. International Scholarly Research Notices, 13(1), pp.1-14.

- Yin, M. Wu, C.Lou, Y. Burda, C. Koberstein, J. T. Zhu, Y. and O’Brien, S. (2005) 'Copper Oxide Nanocrystals'. Journal of the American Chemical Society.127 (26). pp. 9506 -9511.

- Yuan, G. Jiang, H. Lin, C. and Liao, S. (2007) 'Shape- and Size-Controlled Electrochemical Synthesis of Cupric Oxide Nanocrystals' Journal of Crystal Growth, 303 (2). pp.400-406. 
- Yuan, T.K. Shu, M.Y and Kuo.C.L.(2019) 'Synthesis and photocatalytic properties of CuO$\mathrm{CuS}$ core shell nanowires ' Journal of materials, 7(12).pp 1106.

- Xia, Y.; Pu, X.; Liu, J.; Liang, J.; Liu, P.; Li, X.; Yu, X. (2014) ' CuO nanoleaves enhance the c-Si solar cell efficiency Journal of materals chemistry A, 2(19), 6796. 